\title{
El léxico: miradas teóricas, clases textuales y propuestas para la enseñanza
}

\author{
Mabel Giammatteo e Hilda Albano (Eds.). El léxico. De la vida \\ cotidiana a la comunicación cibernética, $1^{\mathrm{a}}$ ed. Buenos Aires: \\ Biblos, 2012, 242 págs.
}

Estela Picón

Universidad Nacional de Salta

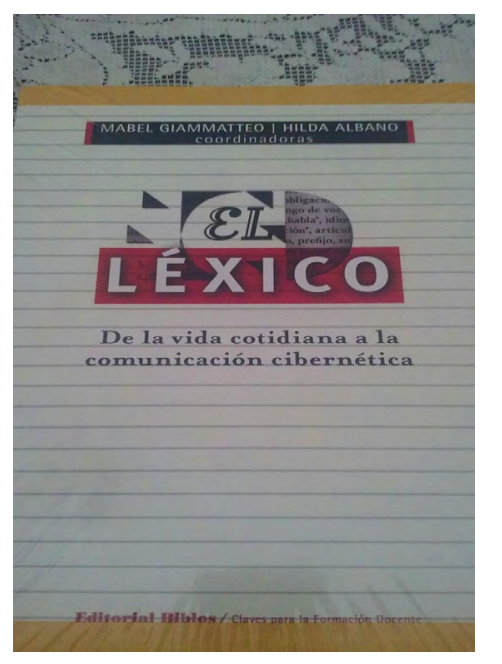

Mabel Giammatteo e Hilda Albano, profesoras e investigadoras de la Facultad de Filosofía y Letras de la Universidad Nacional de Buenos Aires, han dirigido numerosos proyectos sobre el léxico y su relación con la gramática y el aprendizaje. Además del libro coordinado por ellas, El léxico. De la vida cotidiana a la comunicación cibernética, han publicado juntas ¿Cómo se clasifican las palabras? (2006) y Lengua. Léxico, gramática y texto. Una propuesta para la enseñanza basada en estrategias múltiples (2009). Mabel Giammatteo, además, es autora de Lenguaje, discurso e interacción en los espacios virtuales (2014), en colaboración con Alejandro Parini, El Lenguaje en la comunicación digital (2016) y El español en la red (2017). Hilda Albano, miembro de la Academia Argentina de Letras, ha escrito Temas gramaticales para el corrector y el traductor de textos (2014), en coautoría con Alicia María Zorrilla, y Claves gramaticales del español (2015).

El léxico ha sido estudiado desde diferentes perspectivas teóricas en Argentina. Guiomar Ciapuscio, directora del Instituto de Filología y Literaturas Hispánicas “Dr. Amado Alonso", quien trabaja en el marco de los estudios del texto, ha formado a numerosos investigadores. Nora Múgica junto a su grupo de trabajo de la Facultad de Humanidades y Artes de la Universidad Nacional de Rosario, ha indagado sobre el léxico desde la óptica de la gramática generativa chomskiana. Reconocidas investigadoras como Ana Fernández Garay, Ana Gerzenstein, Angelita Martínez, Cristina Messineo y Marisa Censabella se dedican a la lingüística indígena, que tiene una extensísima tradición en el país y se desarrolla en centros como el Instituto de Lingüística de la Universidad de Buenos Aires, el Núcleo de Estudios en Lenguas Minoritarias Americanas de Resistencia, Chaco, y el Instituto de Lingüística de la Universidad Nacional de La Pampa. El campo de la sociolingüística, que también cuenta con una amplia trayectoria, ha explorado cuestiones relativas a los préstamos lingüísticos y las transferencias léxicas en situaciones de lenguas en contacto. Algunos investigadores que trabajan desde esta perspectiva son Yolanda Hipperdinger y Elizabeth Rigatuso, de la Universidad del Sur, y en Salta, Ana María Fernández Lávaque, Juana Rodas y Marta Torino, de la Universidad Nacional de Salta, y el grupo de Susana Martorell de la Universidad Católica de Salta. Por otra parte, el Departamento de Investigaciones Lingüísticas y Filológicas, dependiente de la 
Academia Argentina de Letras, posee y genera archivos lexicográficos, brinda asesoramiento lingüístico y estudia aspectos de léxico de la lengua española, más específicamente de las variedades lingüísticas en Argentina. Asimismo, produce acuerdos sobre el idioma, los cuales contribuyen a la actualización de los diccionarios.

El léxico. De la vida cotidiana a la comunicación cibernética es calificado por sus coordinadoras, Mabel Giammatteo e Hilda Albano, como "un verdadero asedio a la palabra". Presentan una serie de investigaciones sobre el léxico, que conjugan abordajes teóricos y reflexiones sobre la práctica docente. Consideran que este tema es relevante en los distintos niveles educativos ya que, mediante la incorporación del léxico, los hablantes conocen el mundo cotidiano y las distintas áreas del saber técnico y especializado, y también ingresan a una sociedad y a una cultura. Expresan, además, que no adoptan solamente una perspectiva lexicográfica, que registra individualmente las palabras, sino en relación con los diferentes contextos en los que se insertan.

La publicación posee diez capítulos, divididos en tres partes: la primera, que comprende los tres capítulos iniciales, se centra específicamente en la palabra. La segunda, que abarca los tres siguientes, examina su enseñanza en la escuela. La tercera se ocupa de los diferentes contextos de uso.

En el primer capítulo, denominado "El 'valor' de la palabra: el léxico como elemento integrador de las competencias lingüística y comunicativa", Mabel Giammatteo e Hilda Albano plantean la importancia del léxico en la comprensión y la producción de textos de los estudiantes, quienes ponen en juego las competencias lingüística y comunicativa. Las autoras adoptan un enfoque cognitivo, que entiende el léxico como una vía de acceso al conocimiento y, juntamente con las estructuras de la lengua, colabora con el desarrollo y la formación del pensamiento crítico y reflexivo. Plantean las interrelaciones entre el sistema de la lengua y el componente léxico: la interfaz que vincula léxico y gramática, por una parte, y la que conecta el léxico y el mundo, por otra. Desde la óptica de la sociolingüística, desarrollan la relación entre léxico y variación y distinguen las variedades diatópicas, diastráticas y diafásicas. Definen, a continuación, los conceptos de "norma", "variedad estándar", "registro coloquial", "registro técnico", "variedad rural", "lenguas en contacto", entre otros.

En el capítulo dos, "Del diccionario al uso", Guillermina Pagani, reflexiona sobre la función pedagógica del diccionario, instrumento imprescindible en la escuela para enseñar el funcionamiento gramatical y pragmático de las palabras tanto de la lengua materna como de otras lenguas, y herramienta indispensable para la comprensión y la producción de textos. Desde la perspectiva lexicográfica expone los principios que rigen la elaboración de un diccionario. Alude, luego, a los diccionarios lingüísticos y no lingüísticos, a la macro y microestructura del diccionario monolingüe, al significado principal y figurado, a la definición como expresión del significado y a sus tipos. Considera luego la enseñanza del uso del diccionario y se refiere a los diferentes usuarios de esa clase de textos. 
En el capítulo tres, "De lo desconocido a lo conocido: la "definición" como habilidad cognitivo-lingüística en el ámbito escolar", Mariana Cuñarro y María Paula Bonorino indagan sobre la definición, la que consideran un primer acercamiento para la explicación y la comprensión del mundo. Aluden a los tipos de definiciones establecidos por Ignacio Bosque -propias o parafrásticas e impropias o metalingüísticas- y Robert Martin -naturales y convencionales. Con respecto a las relaciones léxicas vinculadas a la definición, caracterizan las de antonimia, sinonimia, hiperonimia y meronimia. Examinan, además, su manifestación en géneros discursivos como el diccionario, el manual escolar y la enciclopedia de divulgación, todos ellos usados en el nivel medio de enseñanza. Evalúan las estrategias que utilizan alumnos de este nivel en la producción de definiciones.

En el capítulo cuatro, "La alfabetización inicial y la escritura de las primeras palabras", Marta Lescano plantea que una persona alfabetizada es quien no solo conoce y usa las palabras de una lengua, sino que logra incluirse como productor creativo y receptor crítico en el entramado de las prácticas sociales del lenguaje de su época. Se enfoca en los procesos de compresión y la producción textual en el nivel inicial y primario, en los que no se prioriza la reflexión sobre el sistema de la lengua, sino las prácticas culturales mediante las cuales los diferentes grupos sociales se vinculan con la escritura. Alude, luego, a las condiciones didácticas para la alfabetización de niños de cinco y seis años y reflexiona sobre la importancia del conocimiento situado y de la inserción temprana de los alumnos pequeños en la cultura escrita.

En el capítulo 5, "La palabra en la construcción del conocimiento. La educación lingüística transdisciplinar en la escuela secundaria”, Patricia García razona sobre las dificultades de los estudiantes de nivel superior y de secundaria para comprender y producir textos en las disciplinas. Desarrolla el concepto de transdisciplinariedad, ligado a la movilidad de los significados de las palabras en el entretejido cultural sobre el que se asientan las diferentes áreas del conocimiento. Plantea estrategias para aprender nuevos términos que corresponden a conceptos de una disciplina, a partir del aporte de vocablos provenientes de otros ámbitos. Considera los aportes transdisciplinares desde la lingüística hacia otras áreas de conocimiento, especialmente la caracterización de los géneros conceptuales, cuya finalidad es hacer de su contenido el objeto de conocimiento. A continuación, expone las estrategias del texto expositivo-explicativo -ejemplificación, paráfrasis, comparación, analogía, metáfora, clasificación.

El sexto capítulo, "Léxico, gramática y ortografía. La puntuación en la escritura y la comprensión de textos", escrito por Marta Raventos, se ocupa del uso de los signos de puntuación en relación con la comprensión integral del texto. La autora sostiene que este sistema de signos gráficos es mucho más abarcativo que el resto de las reglas referidas al uso de letras y tildes -ya que incide en la oración, el párrafo y el texto completo-, más ambiguo y más dependiente del criterio estilístico del autor. Relaciona la puntuación con la sintaxis de los textos, con el significado que el autor quiere transmitir y con la entonación que él imaginó al escribir. Añade una breve historia de los signos de puntuación y desarrolla luego las funciones sintácticas y semánticas que cumple cada signo. Finalmente realiza indicaciones prosódicas. 
En el séptimo capítulo, "La perspectiva léxica en la comprensión del texto literario", Liliana Pazo expresa que la palabra es el punto de articulación entre la estructura de la lengua y los efectos de sentido que propone la literatura. Se aproxima al estudio de la palabra literaria desde la perspectiva de la retórica y la semántica cognitiva. Explica que el discurso literario permite desarrollar cognitivamente la nominación expresivo-vocativa, que designa en relación con el enunciador y manifiesta el valor afectivo, desiderativo, estético, moral, que este le atribuye en el texto. Aborda la "figura" como la mínima unidad estructural en un modelo de retórica y la traslación como condición básica del lenguaje figurado. Desarrolla, además, los tipos de metáforas, e incluye la noción de metáfora cotidiana, acuñada por Lakoff. Además, plantea las dificultades que genera en los estudiantes la comprensión del léxico de los textos literarios, debido a que este se les presenta como difuso e impreciso, poseedor de una amplia capacidad metafórica e innovadora.

En el octavo capítulo, "El léxico en la polémica”, Adalberto Ghio se centra en las palabras de los textos argumentativos polémicos. Distingue las relaciones de designación, que afectan a los significados de las palabras y forman parte del sistema lingüístico, de las relaciones de significación, que conectan los signos lingüísticos con los objetos a los que se refieren. A partir de la noción de campos asociativos -que establecen asociaciones culturales configuradas desde la ideología de los enunciadores-, explica de qué manera juegan las palabras antagónicas en la expresión de los argumentos opuestos.

En el noveno capítulo, "La palabra en la diversidad: el legado léxico de los pueblos originarios", Marcela Lucas plantea la situación multilingüe en Argentina, en la que se hablan lenguas indígenas como el guaraní, el mbyá, el mapudungún, el pilagá, el toba/qom, el wichí, entre otras, y lenguas de inmigración. Relaciona las lenguas minoritarias y las que se perdieron -como por ejemplo las de comechingones, huarpes, charrúas, tonocotés, sanavirones- con procesos dolorosos que culminaron con la muerte de sus hablantes y de sus culturas. Desarrolla, además, fenómenos de contacto y variación lingüística, que tienen una fuerte repercusión en el ámbito educativo, ya que las escuelas tienen la obligación de valorar las lenguas de origen de sus estudiantes y alfabetizarlos en ellas.

En el décimo capítulo, "La palabra en la red: características lingüísticas de la comunicación en internet", Mabel Giammatteo e Hilda Albano caracterizan la comunicación en internet, la que definen como un híbrido entre la oralidad y la escritura, una constelación de lectos y registros, que varían en función de los distintos géneros e intereses. Describen especialmente las modalidades correspondientes a las redes sociales como Twitter, Facebook y Fotolog, desde donde se producen textos fundamentalmente dinámicos, en los que predomina la función emotiva. Con relación a las palabras, presentan sus particulares rasgos tipográficos, ortográficos, morfológicos, estructurales y especifican el léxico del ciberlenguaje, que se destaca por su creación constante, la alternancia de código, las resemantizaciones, los coloquialismos y expresiones propias de la lengua juvenil, los términos apelativos y expresivos y las interjecciones.

Cada uno de los capítulos incluye ejemplos de aplicación de las nociones a los textos y propuestas de enseñanza para distintos niveles educativos. Algunas actividades se enfocan en un 
tema: el reconocimiento del significado de palabras en textos de diversos lectos y registros, el uso del diccionario en el aula, la producción de definiciones en el nivel medio, el funcionamiento de los signos de puntuación. Otras se orientan más hacia los procesos de comprensión y redacción de textos: la lectura en preescolar y primer grado, el análisis de tres cuentos, la comparación de campos asociativos en un texto argumentativo y otro expositivo, el análisis lingüístico-discursivo de textos de redes sociales en los que se emplea la variedad rioplatense. Otras se abordan desde una perspectiva más amplia, como en el quinto capítulo, en el cual se propone trabajar distintas habilidades cognitivas vinculadas con la transdisciplinariedad, y en el noveno, en el que se plantea la reflexión sobre la educación en contextos de diversidad lingüística.

El léxico. De la vida cotidiana a la comunicación cibernética es un libro que, desde la lexicografía, la semántica, la retórica, la sociolingüística y la psicolingüística, se aproxima a las problemáticas vinculadas con el léxico. Dirigido a investigadores, a docentes y también a un público más amplio, indaga sobre la importancia que los distintos niveles educativos deben darle al estudio de la palabra para optimizar las habilidades de comprensión y producción textuales. Es, por tanto, de lectura imprescindible. 